\title{
XII. The diffusion of light
}

\section{W. E. Sumpner D.Sc.}

To cite this article: W. E. Sumpner D.Sc. (1893) XII. The diffusion of light, Philosophical Magazine Series 5, 35:213, 81-97, DOI: 10.1080/14786449308620338

To link to this article: http://dx.doi.org/10.1080/14786449308620338

$$
\text { 曲 Published online: } 08 \text { May } 2009 .
$$

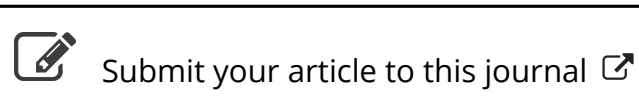

\section{Article views: 5}

Q View related articles $₫$

4 Citing articles: 1 View citing articles 
LONDON, EDINBURGH, AND DUBLIN

\title{
PHILOSOPHICAL MAGAZINE
}

\author{
AND \\ JOURNAL OF SCIENCE.
}

[FIFTH SERIES.]

$F E B R U A R Y 1893$.

XII. The Diffusion of Light. By W. E. Sumpner, D.Se:"

T ITILE information appears to have been published about the diffusing power of unpolished surfaces. The subject has been studied by optical measurements by Zöllner and others, chiefly for astronomical purposes ; and the radiation from such surfaces has also been investigated with apparatus designed for measuring radiant heat. But the influence of such diffusion in increasing the illumination of rooms and open spaces, although well known, does not appear to be appreciated to the extent that its importance deserves; and a few numerical determinations of the coefficients of reflexion, absorption, and transmission of diffusing surfaces may prove of interest.

Terms in light are used vaguely, and it will not be deemed out of place to define those which will be here needed. By the reflecting power of a surface is meant the ratio of the amount of light reflected by it to the total amount of light incident upon it. The illumination of a surface is the amount of incident light per unit area of the surface. The unit quantity of light is the flux of radiation per second across a unit area of a sphere of unit radius at whose centre a unit light (of one candle) is placed. The amount of light radiated by a source of $k$ candle-power, within a solid angle $\Omega$, is $k \Omega$, and the total quantity of light emitted by it is $4 \pi k$. The brightness of a diffusing surface is its candle-power per unit

* Communicated by the Physical Society : read Dec. 9, 1892.

Phil. Mag. S. 5. Vol. 35. No. 213. Feb. 1893.

G 
area in the direction normal to the surface. The illumination produced at a point by a surface of brightness $B$, subtending a (small) solid angle $\dot{\Omega}$ at the point, is $\mathrm{B} \Omega$, and if a surface, containing this point, have its normal inclined at an angle $\phi$ to the axis of $\Omega$, the illumination of this second surface due to the first is $B \Omega \cos \phi$.

If $B$ is the brightness of a surface rendered luminous by reflexion, if $\eta$ is its (diffused) reflecting-power, and if $I$ is the illumination of the surface, then

$$
\pi \mathrm{B}=\eta \mathrm{I} \text {. }
$$

This relation follows from the assumption of the law of cosines, viz. that the candle-power (per unit area) of a bright surface is $\mathrm{B} \cos \phi$ in a direction making an angle $\phi$ with the normal. The right-hand nember of (1) is by definition equal to the whole light reflected from unit area of the surface, and must be equal to the integral of $\mathrm{B} \cos \phi d \Omega$ for all directions on one side of the surface. The value of the integral is ensily seen to be $\pi \mathrm{B}$.

The brightness of a body, as just defined, is directly proportional to the illumination of the image of the body on the retina of the eye, and the word may thus be quite justly used in the ordinary physiological sense of the term. Similarly the law of cosines, just alluded to, is merely another way of expressing the fact that the sensation of the brightness of a diffinsing surface is the same from whatever direction this surface may be viewed. For the amount of light received by the eye, and concentrated on the image on the retina, is simply the product of the area of the pupil of the eye and the illumination at the surface of the eye due to the bright abject. The former tactor is constant for different directions of view, and the latter must vary as the solid angle subtended by the object at the eye, since the area of the image on the retina is a moasure of this solid angle. 'The illumination at a point at which a surface of brightness $B$ subtends a solid angle $\Omega$ is not necessarily $B \Omega$ for all inclinations of $\Omega$ to the surface, unless the law of cosines is fulfilled; and, if this law is fulfilled, it follows that the illumination of the image of this surface on the retina of the eye is constint at all distances and inclinations. The eye is a good judge, and is indeed the only judge, of quick variations in brightness, and the cosine law is always applicable to diffusing surfaces, the appearance of which does not alter as the eye moves past them. Any divergence from this law is negligible so far as its influence on illumination is concerned.

If $Q$ is the quantity of light radiated per second by the 
light-sources within a room, and if $Q^{\prime}$ is the total amount of light falling on the walls,

$$
\mathrm{Q}^{\prime}=\mathrm{Q}+\eta \mathrm{Q}^{\prime} \text {. . . . . . . }
$$

For of the quantity $\mathrm{Q}^{\prime}$, a portion $\eta \mathrm{Q}^{\prime}$ must be reflected, and the rest absorbed, and the rate at which light is absorbed by the walls must be equal to the rate at which it is produced. The average illumination $\mathrm{I}^{\prime}$ of the walls of the room must hence be related to $I$, the illumination due to the direct action of the lights, by the equation

$$
\mathrm{I}^{\prime}=\frac{1}{1-\eta} \mathrm{I} . \quad \cdot \quad \cdot \quad \cdot \quad \cdot \quad . \quad .
$$

Thus if $\eta=\cdot 90, \mathrm{I}^{\prime}=10 \mathrm{I}$, and if $\eta=\cdot 50, \mathrm{I}^{\prime}=2 \mathrm{I}$, so that the illumination due to the walls of the room may become far more important than that caused by the direct rays of the lights.

The truth of this relation may be also seen as follows:The light $Q$ falling on the walls is partially reflected, and a quantity $\eta \mathrm{Q}$ is sent back into the room. This light falls on the walls again and a portion $\eta \times \eta \mathrm{Q}$ is reflected a second time. The total quantity of light $\mathrm{Q}^{\prime}$ falling on the walls owing to successive reflexions is given by the equation*

$$
\mathrm{Q}^{\prime}=\mathrm{Q}+\eta \mathrm{Q}+\eta^{2} \mathrm{Q}+\ldots=\frac{1}{1-\eta} \mathrm{Q} \text {. }
$$

Or, again, as the illumination $\mathrm{I}_{p}{ }^{\prime}$ of the walls at any point $\mathrm{P}$ is made up of a portion $I_{p}$ due to the direct rays of the lights, together with a part caused by radiation from the walls, wo have

$$
\mathrm{I}_{p}^{\prime}=\mathrm{I}_{p}+\int \mathrm{B} \cos \phi d \Omega, \quad . \quad . \quad .
$$

where $B$ is the brightness of the walls, and $\phi$ is the inclination of the solid angle $d \Omega$ to the normal to the surface at the point $P$. Assuming that the brightness is the same all over the bounding surface of the room, the value of the integral is readily soen to be $\pi \mathrm{B}$, and this, as already shown, is equal to $\eta \mathrm{I}^{\prime}$, where $\mathrm{I}^{\prime}$ is the average illumination of the walls.

When the bounding surface of a room or enclosure consists of portions whose reflective powers are different, the average reflective power may be taken as

$$
\eta_{m}=\frac{\eta_{1} \mathrm{~A}_{1}+\eta_{2} \mathrm{~A}_{2}+\& \mathrm{c} . \ldots}{\mathrm{A}}, . . .
$$

* Since writing this paper I have discovered that this relation has been already pointed out by Mascart [see Palaz, Tratité de Phatometrie fndustrielle, p. 268]. 
where $A$ is the total aren of the bounding surface, of which a portion $A_{1}$ has a reflective power equal to $\eta_{1}$, and a second portion $A_{2}$ a reflective power $\eta_{2}$, \&c. This relation is very approximately true for ordinary rooms, and may be shown to be quite accurate for a spherical enclosure.

Fig. 1.

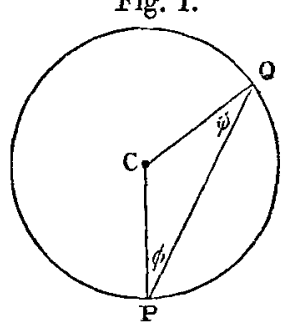

For let $\mathrm{P}$ and $\mathrm{Q}$ be any two points of a sphere of centre $\mathrm{C}$ and radius $r$ (fig. 1). Then $P Q=2 r \cos \phi$, where $\phi$ is the angle which the chord makes with the radius through either $\mathrm{P}$ or Q. Also, with the same notation as before, we have

$$
\mathrm{I}_{p}^{\prime}=\mathrm{I}_{p}+\int \mathrm{B} \cos \phi \frac{d \mathrm{~A} \cos \phi}{\mathrm{PQ}^{2}},
$$

where $d \mathrm{~A}$ is an element of area at $\mathrm{Q}$ of brightness $\mathrm{B}$, and subtending a solid angle $d \mathrm{~A} \cos \phi / \mathrm{PQ}^{2}$ at $\mathrm{P}$. Now $\mathrm{PQ}^{2}=4 r^{2} \cos ^{2} \phi$ and $\pi \mathrm{B}=\eta \mathrm{I}^{\prime}$, where $\mathrm{I}^{\prime}$ is the illumination of the area $d A$ : hence

$$
\mathrm{I}_{p}^{\prime}=\mathrm{I}_{p}+\frac{1}{4 \pi r^{2}} \int \mathrm{I}^{\prime} \eta d \mathrm{~A}=\mathrm{I}_{p}+\frac{1}{\mathrm{~A}} \int \mathrm{I}^{\prime} \eta d \mathrm{~A}, .
$$

A being the total area of the spherical surface. The integral is constant whatever the position of the point $P$, and whatever the character of the reflecting surface of the spbere. Thus if any complete [or if any portion of a] spherical surface be illuminated in any manner $\mathrm{I}_{p}$ by the direct rays of a combination of light sources, the actual illumination $\mathrm{I}_{p}{ }^{\prime}$ will exceed $I_{p}$ by a constant amount all over the sphere, owing to the reflective action of the surface. Also, if the original distribution be uniform all over the sphere, $I_{p}=I$, a constant, $\mathrm{I}_{p}{ }^{\prime}$ will also be constant, $=\mathrm{I}^{\prime}$, and

$$
\mathrm{I}^{\prime}=\mathrm{I}+\frac{\mathrm{I}^{\prime}}{\mathrm{A}} \int \eta d \mathrm{~A}=\mathrm{I}+\eta_{m} \mathrm{I}^{\prime},
$$

where

$$
\eta_{m}=\frac{\Sigma \eta d \mathrm{~A}}{\mathrm{~A}} \text {. . . . . . . }
$$


Taking as an average case for rooms a reflecting power of 70 per cent. for the ceiling, 40 per cent. for the walls, and 20 per cent. for the floor, the average value of $\eta$ is a little over 40 per cent., and the increase of illumination by reflexion becomes as much as 70 per cent. If the walls and ceiling of a room be well whitewashed, the average reflecting power will not fall far short of 80 per cent.; and in such cases the illumination due to diffused reflexion is four times as important as that caused by the direct action of the lights in the room. A further great advantage, resulting from the use of good diffusing surfaces, arises from the fact that the illumination they cause is, in most cases, very approximately constant all over the room, and does not cast shadows.

It is to be noted that when a reflecting surface is coloured, its average reflecting power does not properly represent the character of the increase of illumination caused by it. A room whose walls are covered with red paper whose average reflecting power is 40 per cent., may quite possibly have the red light in the room increased five times owing to the action of the walls. Suppose, for instance, that the reflective power of the paper for red light is 80 per cent., and for other kinds of light only 10 per cent., the average reflecting power will not exceed 40 per cent., yet the red light will be increased five times, while other kinds of light will not be inereased to any perceptible extent.

\section{Measurements of Reflective Power.}

The surface, whose reflective power was required, was attached to a large screen of black velvet placed at one end $O$ of a 3-metre photometer-bench OL (see fig. 2), so as to

Fig. 2.

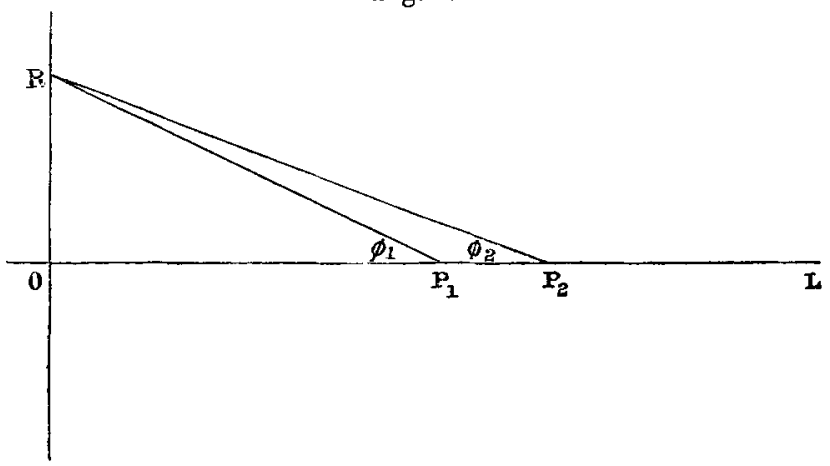

be perpendicular to its length. Two lights were used, one being a Methven two-candle gas standard, placed at $\mathrm{L}$, and 
the other a glow-lamp run generally at about 20 candlepower, placed at $P_{1}$. A Lummer-Brodhun photometer was slid along the bench to a point $P_{2}$ at which the illumination due to reflexion from the surface $O R$ was equal to that due to the Methven standard at $L$. At first the lamp $P_{1}$ was permanently situated a little to one side of the bench, and the rays from it in the direction of the photometer $P_{2}$ were screened off. Subsequently the points $P_{1}$ and $P_{2}$ were made to coincide, the lamp being fixed to the same slider as the photometer and suitably screened from it and from the eyes of the observer. In some experiments the distance OL was kept fixed and the position of balance OP was determined for each surface tested. In other cases both UP and OI. were varied.

Let :-

$A=$ area of diffusing surface on screen OR (centre at $O$ ). $\boldsymbol{\Omega}_{1}, \boldsymbol{\Omega}_{2}=$ solid angles subtended by $\mathbf{A}$ at $\mathbf{P}_{\mathbf{y}}, \mathbf{P}_{\mathbf{2}}$ respectively. $x_{1}, x_{2}=$ distances $\mathrm{OP}_{1}, \mathrm{OP}_{2}$ respectively.

$y=$ distance $\mathrm{P}_{2} \mathrm{~L}$.

$K=$ candle-power of the glow-lamp at $\mathrm{P}_{\mathrm{r}}$.

$k=$ candle-power of Methven standard at $\mathrm{L}$.

Then :-

The quantity of light falling on the area $A$ is $K \Omega_{3}$,

the average illumination of $A$ is $K \Omega_{1} / A$,

the average brightness is $\eta \mathrm{K} \Omega_{\mathrm{j}} / \pi \mathrm{A}$, by (1),

the illumination at $P_{2}$ is $\eta K \Omega_{1} \Omega_{2} / \pi A$,

and also the illumination at $\mathrm{P}_{2}$ is $k / y^{2}$; whence

$$
\eta=\frac{k}{\mathrm{~K}} \frac{\pi \mathrm{A}}{\Omega_{1} \Omega_{2} y^{2}}=\frac{k}{\mathrm{~K}} \frac{\pi x_{1}^{2} x_{2}^{2}}{\mathrm{~A} y^{2}}, \ldots . .
$$

provided the dimensions of $\mathrm{A}$ are small compared with $x_{1}$ or $x_{2}$. When this is not the case, the equation (8) is not sufficiently correct, and a more accurate formula may be obtained as follows, by taking note of the inclination of the rays to the surfaces.

The illumination of the surface at the point $R$ due to the lamp at $P_{1}$ can be easily shown to be $K \cos ^{3} \phi_{1} / x_{1}{ }^{2}$, where $\phi_{1}$ is the angle between $R P_{1}$ and $O L$, the line of centres of the bench. The brightness $B$ of the surface at $\mathbf{R}$ is therefore $\eta \mathrm{K} \cos ^{3} \phi_{1} / \pi x_{1}{ }^{2}$ by equation (1). An element of area $d \mathrm{~A}$ at $\mathrm{R}$ subtends at $\mathrm{P}_{2}$ a solid angle $d \Omega_{2}$ equal to $\cos ^{3} \phi_{2} d \mathrm{~A} / x_{2}{ }^{2}$, and the illumination at $P_{2}$ due to this element is $\mathrm{B} d \Omega_{2}=$ $\eta \mathrm{K} \cos ^{3} \phi_{1} \cos ^{3} \phi_{2} d \mathrm{~A} / \pi x_{1}^{2} x_{2}^{2}$ on any area placed perpendicular to $\mathrm{RP}_{2}$. As the photometer screen is perpendicular to the 
Dr. W. E. Sumpner on the Diffusion of Light.

bench and not to $\mathrm{RP}_{2}$, we must multiply this expression by $\cos \phi_{2}$ to get the effective illumination due to the element $d A$. Finally we have for the total illumination the integral :-

$$
\mathrm{I}=\frac{\eta \mathrm{K}}{\pi x_{1}{ }^{2} x_{2}{ }^{2}} \int \cos ^{3} \phi_{1} \cos ^{4} \phi_{2} d \mathrm{~A}, \ldots . .
$$

in which the angles $\phi_{1}, \phi_{2}$ are related by the equation

$$
x_{1} \tan \phi_{1}=x_{2} \tan \phi_{2} \text {. }
$$

When the area $A$ is circular, with $O$ as its centre, this integral reduces to

$$
\mathrm{I}=\frac{\eta \mathrm{K}}{x_{1}^{2}} \int \cos ^{3} \phi_{1} d \cdot \sin ^{2} \phi_{2} . \quad \text {. . . }
$$

The value of this integral can be readily evaluated, but it does not lead to a convenient formula, and as it was found practically preferable to fix the lamp to the same slider as the photometer, and at the same distance from the screen OR, we may put

and (10) then reduces to

$$
\begin{aligned}
& \phi_{1}=\phi_{2}=\phi, \\
& x_{1}=x_{2}=x,
\end{aligned}
$$

$$
\mathrm{I}=\eta \frac{\mathrm{K}}{\bar{x}^{2}} \frac{2}{5}\left[1-\cos ^{5} \phi\right], . . . . .
$$

in which $\phi$ is the semiangle of the cone with base $A$ and height $x$.

This expression is rendered more convenient for purposes of calculation by taking advantage of the fact that $A / \pi x^{2}$, or $\tan ^{2} \phi$, is a small quantity. By neglecting $\tan ^{6} \phi$ compared with unity we obtain

where

$$
\frac{2}{5}\left[1-\cos ^{5} \phi\right]=\frac{1}{\mathrm{X}}
$$

$$
\mathrm{X}=\frac{\pi x^{2}}{\mathrm{~A}}+1 \cdot 75+\cdot 13 \frac{\mathrm{A}}{\pi x^{2}}, \ldots . . .
$$

and in most cases it will be found that the third term in this expression is negligibly small compared with the sum of the other two.

The value of I found in (11) may be equated to $k / y^{2}$ when the photometer is in the position of balance, and on doing so, we find for $y$ the value

$$
\eta=\frac{k}{\mathrm{~K}} \frac{x^{2}}{y^{2}} \mathrm{X}, \quad . \quad \cdot \quad \cdot \quad \cdot \quad \cdot
$$

which reduces to (8) when $x$ is large. 
This equation was used for the great majority of the reflexion tests. With feebly diffusing surfaces such as black oloth, the distance $x$ had to be so much reduced that the area A subtended a greater angle at the photometer screen than the aperture of the photometer itself. In such cases the angle $\phi$ in (11) was calculated from the solid angle subtended by the aperture of the photometer at the centre of the photometer screen. With diffusing surfaces which appeared to shine slightly under the action of light the effect of regular refiexion had to be separated from that of diffused reflexion, by experiments made with the same surface for different values of $x$. In such cases, which will be alluded to subsequently, the true reflecting-power is not given by formula (13). The areas $A$ of the reflecting surfaces used in the experiments were never circular, as assumed in the above proof, but as they were always approximately square, with the central portion at $O$ (fig. 2), any error in (12) and (13) arising in this way must be quite negligible. The ratio $k / \mathrm{K}$ of the two lights was frequently tested in the course of the experiments and was found very constant during every set of tests.

The results obtained are given in the accompanying table. In the majority of cases the numbers given are approximate only, as there seemed no object in aiming at great accuracy. The first four surfaces referred to in the table, viz., thick white blotting-paper, white (rough) cartridge-paper, tracingpaper, and tracing cloth, were, however, carefully tested, and the numbers obtained represent the mean of many observations.

\section{TABLE I.-Reflecting-Powers.}

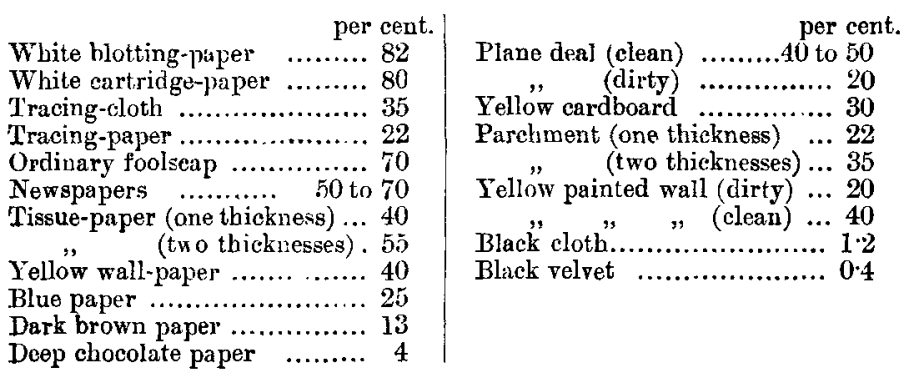

Zöllner found white surfaces to reflect from 70 to 78 per cent. of the light incident upon them. The numbers given at the head of the above table are slightly higher. They, lowever, agree very well with results which have been pub- 
lished with regard to the diffuse reflexion of radiant heat, since 82 per cent. is generally given as the reflective power of white substances*.

The degree of consistency of the results may be judged as follows:-In a series of 10 determinations of the reflective power of white blotting-paper, made with values of $x$ (see fig. 2), varying from $40 \mathrm{~cm}$. to $82 \mathrm{~cm}$., the mean reflecting power was found to be 82.4 per cent., and the average error of a single deteruination from the mean was 1.4. With surfices of lower reflecting-power (such as tracing-cloth) the numbers obtiined in successive experiments were more consistent. The value of $\boldsymbol{\eta}$ for white blotting-paper was checked by comparing it directly with that of a piece of common mirror. The Methven standard at L (see fig. 2) was replaced by the mirror, arranged so as to reflect the light from the glow-lamp along the line of the bench. The reflective power of the white blotting-paper placed on the screen OR was found to be 98.5 per cent. of that of the mirror. The value of $\eta$ for the mirror, for normal rays, was separately determined and found to be 82 per cent., and hence $\eta$ for the blotting-paper comes out as 80.8 per cent.

Several of the numbers in the above table were confirmed by comparative measurements, using white paper as a standard reflector, the Methven standard at $L$ (fig. 2 ) being replaced by a surface of white paper exposed to the rays of the glowlamp at $P$. The reflective power of one of the walls tested was measured in diffuse daylight by exposing the aperture of a photometer to the radiation of the wall, and balancing the illumination against that of a standard candle. The part of the wall affecting the photometer was then covered with a sheet of white blotting-paper, and the ratio of the two illuminations at once gave the ratio of the reflecting-powers.

\section{Measurement of Absorption.}

The absorbing-powers of some of the preceding substances were determined by measuring the candle-power of the light from a glow-lamp, first when this was uncovered, and afterwards when it was surrounded with a cylinder of the paper under test. The cylinders were short, being just longer than the height of the lamp, and were closed at top and bottom with caps of the same paper, so that the lamp was completely

* See Jamin et Bouty, Torne Troisième, p. 149. Results by MM. Goddard, De la Provostaye et Desains. 
enveloped by the paper tested. The ratio of the diminution of candle-power to the original candle-power gave the apparent absorption of the paper. If the candle-power in some particular case was found to diminish 30 per cent., it would have been erroneous to conclinde that the envelope absorbed as much as 30 per cent. of the light incident upon it, or that 70 per cent. was transmitted. If the reflecting, absorbing, and transmitting powers of a material be respectively denoted by $\eta, a$, and $\tau$, there must exist between these quantities the relation

$$
\eta+a+\tau=1 \text {. }
$$

Also if $Q$ be the quantity of light given out per second by the light-source within the envelope, the quantity of light incident per second upon the surface of the envelope will, owing to internal reflexion, be increased to $Q^{\prime}$, where

$$
\mathrm{Q}^{\prime}(1-\eta)=\mathrm{Q}
$$

the quantities of light absorbed and transmitted will respectively be

$$
a Q^{\prime} \text { and } \tau Q^{\prime} \text {, }
$$

and the ratios these quantities bear to $Q$ will similarly be

$$
\frac{\alpha}{1-\eta} \text { and } \frac{\tau}{1-\eta} \text {; }
$$

the sum of course being unity.

If the light-source can be assumed to radiate equally in all directions, the ratio of its candle-power, after putting on the envelope, to the original candle-power will not be $\tau$ but $\pi /(1-x)$. The influence of internal reflexion is to increase both the absorption and the transmission, and unless it is taken into account large errors may be made in estimating the coefficients. A very simple way of showing the effect of internal reflexion consists in surrounding a glow-lamp with a white paper cylinder, open at the top, and adjusting a photometer screen till the illumination caused by it is balanced against that of some standard source of light. If now a piece of white paper be placed on the top of the cylinder, so as to shut in the vertical rays of the lamp, the candle-power in the horizontal direction will be found to increase considerably. In some of the tests, in order to avoid error caused by nonuniform radiation of the lamp, this was first surrounded with an envelope of tracing-cloth, or blotting-paper, and the combination used as the light-source. If $k_{0}$ be its candle-power in this condition, and if $k_{1}$ be the observed candle-power after completely surrounding it with an envelope of the sub- 
stance to be tested, the apparent absorption of this material is

$$
\frac{k_{0}-k_{1}}{k_{0}}, \text {. . . . . . }
$$

and the true absorption coefficient $\alpha$ is given by

$$
\alpha=(1-\eta) \frac{k_{0}-k_{1}}{k_{0}}, . . . \quad .
$$

where $\eta$ is the previously fornd reflexion coefficient.

When an inner envelope is used to produce a light which radiates equally well in all direetions, it is necessary for the outer envelope to be large compared with it, since otherwise the formula for the increase of illumination due to internal reflexion cannot be applied.

The following table gives the values of the absorbing coefficients, expressed as percentages, for the four substances at the head of 'Table I., from which the corresponding values of $\eta$ used in applying (15) have been taken.

\begin{tabular}{|c|c|c|}
\hline & Apparent Absorption. & Keal Absorption. \\
\hline White Blotting-paper ......... & 77 per cent. & 13.8 per cent. \\
\hline White Cartridge-p.uper .. & 61 & 122 \\
\hline Tracing-cloth ............ & 23 & 150 \\
\hline Tracing-paper ............ & 9 & $7 \cdot 0$ \\
\hline
\end{tabular}

TABLE II.

Three large glass globes, made for arc-lamps, were also tested. As the reflective powers of the globes could not easily be found, only the apparent absorption was measured. One globe was of opal glass (almost transparent), and the ratio of apparent absorption was 15 per cent. A second globe was of ground glass and absorbed 42 per cent. The remaining one was of opal glass, too opaque to allow any bright object placed within it to be distinguished. This absorbed 39 per cent.

\section{Measurements of Transmitting-Power.}

The amount of light transmitted through the surfaces above mentioned was measured in a very similar manner to that in which their reflective powers were determined; the 
only difference being that the glow-lamp at $P_{1}$ (see fig. 2) was moved to the opposite side of the surface as in fig. 3 .

OR represents the screen of paper, pinned on a wooden frame, and placed perpendicular to the optical bench $\mathrm{P}_{1} \mathrm{~L}$. The

Fig. 3.

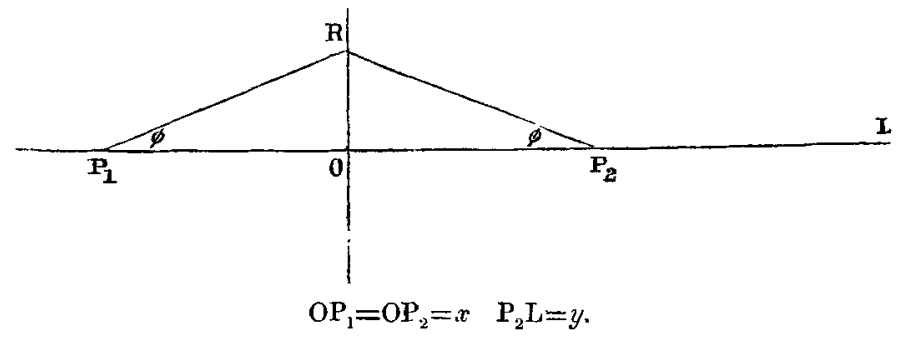

glow-lamp was at $P_{1}$, the photometer at $P_{2}$, and the Methven standard at $\mathrm{L}$. The distances $\mathrm{OP}_{1}, \mathrm{OP}_{2}$ were arranged to be equal, and balance obtained by moving $L$ along the bench. On referring to equations (8) to (13) and the arguments used in establishing them, it will be seen that they are all applicable to the case now considered if only we substitute $\tau$, the transmitting-power, for $\eta$.

When, however, tests were made with the paper surfaces already referred to, it was soon found that the numbers calculated from expression (13),

$$
\frac{k}{\overline{\mathrm{K}}} \frac{x^{2}}{y^{2}} \mathrm{X}=\mathrm{Y}, \cdot \cdot \cdot \cdot \cdot \cdot \cdot
$$

were not constant for the same substance. They differed from each other far more than could be accounted for by errors of experiment; thus, the values found for $\tau$ by this formula were too high, and frequently exceeded 100 per cent. For any given surface the values were found to increase progressively with the value of $x$ used in the tests. The reason for this is easily seen when it is remembered that equations (8) to (13) are only true on the assumption that the surfaces considered are purely diffusive, and do not alter in appearance as the eye changes its point of view. When light is transmitted throngh a semitransparent substance such as tracingpaper, or tracing-cloth, the brightest part of the surface is always on the line joining the eye to the light, and visibly moves over the surface as the point of view is changed. The 
easiest way to represent these facts is to assume that, of the light transmitted, a portion $\tau_{1}$ passes through without change of direction, and that the rest $\tau_{2}$ is diffused in accordance with the cosine law. The case is analogous with a reflecting surface such as white enamelled iron, which reflects a portion $\eta_{1}$ of the incident light in accordance with the regular law of reflexion, and diffuses another portion $\eta_{2}$ according to the law of cosines. On referring to equations (8) to (11) it will be noticed that they are still true for the illumination due to diffusion if we substitute for $\eta$ either $\tau_{2}$ or $\eta_{2}$ (according as we are considering transmission (fig. 3) or reflexion (fig. 2) respectively). The additional illumination at the photometer due to regular, $i . e$. direct, transmission (transparency) is

$$
\tau_{1} \frac{\mathrm{K}}{(2 x)^{2}}, \text {. . . . . . . }
$$

and a similar expression holds for regular reflexion if we substitute $\eta_{1}$ for $\tau_{1}$.

The whole illumination must, as before, be equal to $k / y^{2}$, and by (11), (12), and (17) we have

$$
\tau_{2} \frac{\mathrm{K}}{x^{2} \mathrm{X}}+\tau_{1} \frac{\mathrm{K}}{4 x^{2}}=\frac{k}{y^{2}}, \ldots . . .
$$

whence the value of $\mathrm{Y}$ in (16) is equal to

$$
\mathbf{Y}=\tau_{2}+\frac{\tau_{1}}{4} \mathrm{X} ; \text {. . . . . . }
$$

and a similar expression holds for reflexion if we replace $\tau_{1}$ and $\tau_{2}$ by $\eta_{1}$ and $\eta_{2}$ respectively. The true values for the transmitting and reflecting coefficients are

$$
\left.\begin{array}{l}
\tau=\tau_{1}+\tau_{2}, \\
\eta=\eta_{1}+\eta_{2},
\end{array}\right\} ; . . . . . .
$$

and the reason the values found for $Y$ were too high, and became greater and greater as $x$ increased, was simply that the values used for $X$ (see 12) were always greater than 4 , and increased rapidly with $x$.

By plotting the numbers found for $\mathrm{Y}$ with the corresponding values of $X$, a straight line is obtained from which the values represented by the symbols in (20) can all be determined. The straightness of these lines, and the verification of the fundamental formula

$$
\eta+\alpha+\tau=1
$$


affords a good criterion of the extent to which the principles and the formulæ, referred to in this paper, can be relied upon.

The following Tables III., IV., and V. contain the results of three sets of tests on the transmitting-power of blottingpaper and tracing-cloth, and on the reflecting-power of tracing-cloth. The values of $\mathrm{Y}_{\text {obs. }}$ are calculated with the aid of (12) and (16) from the observed values of $x$ and $y$. All the dimensions are given in centimetre-units. In the accompanying sheet of curres the valnes of $Y_{\text {obs. }}$ are plotted as ordinates, with the corresponding values of $X$ as abscissæ. From the straight line most nearly representing the connexion between the points the values of $Y_{\text {cale. }}$ have been obtained, and are given in the tables. From this straight line also the true value of the transmitting (or reflective) power can be found by finding the value of the ordinate when $X=4$. The intercept on the axis of $\mathrm{Y}$ shows the portion of the light which is liffused.

TABLE III.--Transmitting-Power of Blotting paper.

$\mathrm{A}=980 . \quad \mathrm{K}=26 . \quad k=2 . \quad \tau=9 \cdot 2 . \quad \mathrm{Y}_{\text {eale. }}=6 \cdot 50+2 \cdot 7 \mathrm{X} / 4$.

\begin{tabular}{|c|c|c|c|c|c|c|}
\hline$x \ldots \ldots \ldots \ldots$ & 60 & 50 & 40 & 45 & 55 & 60 \\
\hline$y \ldots \ldots \ldots \ldots$ & 154 & 120 & $88 \cdot 4$ & $104 \cdot 6$ & 137 & 154 \\
\hline $\mathrm{X} \ldots \ldots$ & 136 & 98 & 70 & $8 \cdot 25$ & 11.40 & 136 \\
\hline$Y_{\text {obs. }}$ & $15 \%$ & $13 \cdot 2$ & 112 & $12 \cdot 0$ & $14 \cdot 4$ & $15 \%$ \\
\hline$Y_{\text {cale. }}$ & 157 & $13 \cdot 1$ & $11 \cdot 2$ & $12 \cdot 1$ & $14 \cdot 2$ & 157 \\
\hline
\end{tabular}

Table IV.- Trunsmitting-Power of Tracing-cloth.

$$
\mathrm{A}=980 . \quad \mathrm{K}=291 . \quad k=2 . \quad \tau=54 \cdot 4 . \quad \mathbf{Y}_{\mathrm{calc} .}=41 \cdot 0+13 \cdot 4 \mathrm{X} / 4 \text {. }
$$

\begin{tabular}{|c|c|c|c|c|c|c|c|c|c|}
\hline$x \ldots \ldots$ & 40 & 50 & 60 & 70 & 81) & 75 & 65 & 5.5 & 45 \\
\hline$\% \ldots$ & $3: 2$ & 535 & 701 & $89 \cdot 4$ & $105 \cdot 6$ & $9 \overline{5} 8$ & $77 \cdot 7$ & $6 \mathrm{I}$ & $46 \cdot 1$ \\
\hline $\mathbf{X}$ & 6.98 & 980 & 136 & $17 \cdot 4$ & $22: 30$ & $19 \cdot 4$ & $15 \cdot 4$ & $11 \cdot 2$ & 8.25 \\
\hline $\mathrm{Y}_{\text {obs. }} \ldots$ & 635 & $74: 3$ & $86 \cdot 1$ & 970 & 116 & 107 & $91 \cdot 8$ & $81 \cdot 7$ & $69 \cdot 3$ \\
\hline $\mathbf{Y}_{\text {cale. }} \ldots$ & $6+\cdot t$ & 737 & 856 & $9 \cdot 2$ & 1158 & 106 & $94 \cdot 0$ & 785 & 68.7 \\
\hline
\end{tabular}


TABLE V.-Reflecting-Power of Tracing-cloth (shiny side). $A=1300 . \quad \mathrm{K}=12 . \quad k=2 . \quad \eta=35 \% . \quad \mathrm{Y}_{\text {calc. }}=30 \cdot 9+4 \cdot 8 \mathrm{X} / 4$.

\begin{tabular}{|c|c|c|c|c|c|c|}
\hline$x \ldots \ldots \ldots \ldots \ldots$ & 50 & 55 & 623 & $59 \cdot 8$ & 47.5 & $44 \breve{3}$ \\
\hline$y \ldots \ldots \ldots \ldots$ & 90 & $104 \cdot 4$ & 1277 & $120 \cdot 2$ & 82.5 & $75 \cdot 5$ \\
\hline $\mathrm{x}$ & 7.82 & $9 \cdot 10$ & $11 \cdot 13$ & $10 \cdot 45$ & $7 \cdot 22$ & 6.55 \\
\hline $\mathbf{Y}_{\text {obs. }} \ldots \ldots$ & $40 \cdot 4$ & $41 \cdot 8$ & $44 \cdot 1$ & $43 \cdot 2$ & $39 \cdot 6$ & $28 \cdot 6$ \\
\hline $\mathrm{Y}_{\text {cale. }} \ldots$ & $40 \cdot 3$ & 41.8 & $44 \cdot 2$ & $43 \cdot 4$ & $39 \cdot 6$ & $38 \cdot 7$ \\
\hline
\end{tabular}

Fig. 4.

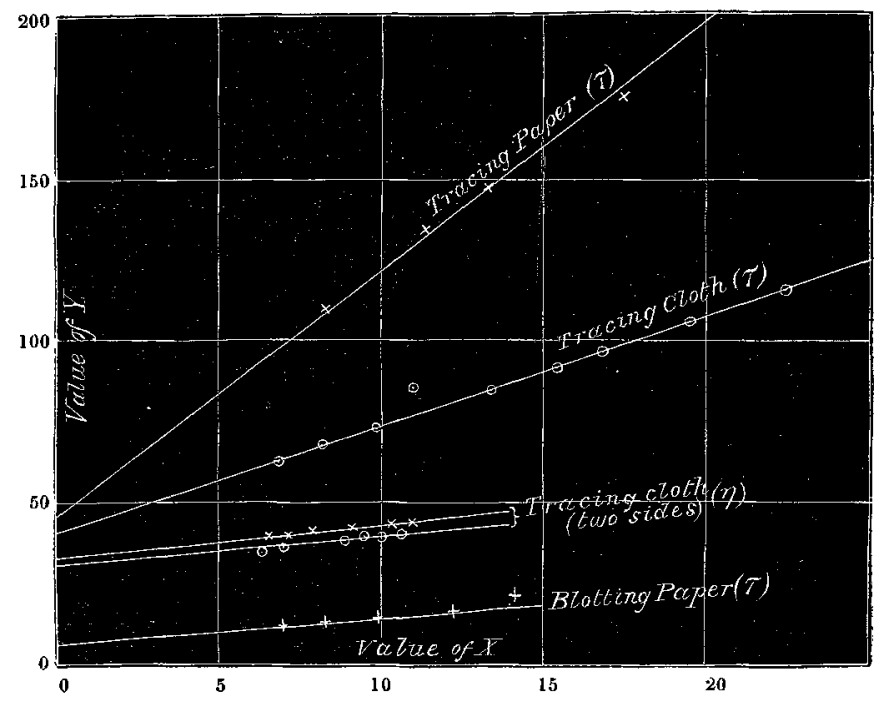

Several sets of tests were taken. Some of these are represented by the sheet of curves shown in fig. 4. $\mathrm{Y}$ is the percentage of the incident light which the surfuce apparently reflects or transmits, assuming that it is all diffused, and is calculated from equation (16). The true values of the coefficients are obtained from the curves by applying equations (19) and (20). The numerical details of the observations are of no special interest, and the essential results may be summarized as follows :- 
Table VI.-Reflective Powers.

\begin{tabular}{|c|c|c|c|}
\hline & $\begin{array}{c}\text { Regular. } \\
\eta_{1} .\end{array}$ & $\begin{array}{c}\text { Diffused. } \\
\eta_{2^{\prime}}\end{array}$ & $\begin{array}{c}\text { Total. } \\
\eta .\end{array}$ \\
\hline Blotting-paper...... & 0 per cent. & 82 por cent. & 82 per cent. \\
\hline Cartridge-paper & $"$ & 80 & 80 \\
\hline Tracing-cloth (shiny side) ... & $4 \cdot 8 \quad$ & $309 "$ & $357 \quad$, \\
\hline$" \quad, \quad$ (rougl side)... & $2 \cdot 7$ & $31 \cdot 6 \quad "$ & 343, \\
\hline Tracing- & $2 \cdot 2$ & $19 \cdot 8$ & 220 \\
\hline
\end{tabular}

TABLE VII.-Transmissive Powers.

\begin{tabular}{|c|c|c|c|}
\hline & $\begin{array}{c}\text { Direct. } \\
\tau_{1} .\end{array}$ & $\begin{array}{c}\text { Diffused. } \\
\tau_{2^{*}}\end{array}$ & $\begin{array}{c}\text { 'Total. } \\
\tau .\end{array}$ \\
\hline Blotting-paper .................. & 27 per cent. & 65 per cent. & $9 \cdot 2$ per cent. \\
\hline Cartridge-paper & $25 \quad "$ & $8 \cdot 7 \quad$ & $11 \cdot 2 \quad$, \\
\hline Tracing-cloth & $13 \cdot 4 \quad$ & $410 \quad$, & $54 \cdot 4$ \\
\hline Tracing-paper & $29 \cdot 8$ & $46 \cdot 2$ & $76 \cdot 0$ \\
\hline
\end{tabular}

We may now collect the coefficients $\eta, \alpha, \tau$, determined by the foregoing independent methods, and compare their sum with unity.

TABLE VIII.

\begin{tabular}{|c|c|c|c|c|c|c|c|c|}
\hline & & $\eta$ & \multicolumn{2}{|c|}{$\alpha}$. & \multicolumn{2}{|c|}{$\tau}$. & \multicolumn{2}{|c|}{$\eta+a+r$} \\
\hline Bluttiug-paper ...... & 82 & er cent. & 1388 & r cent. & $9 \cdot 2$ & r cent. & 105.0 & r cent. \\
\hline Oartridge-paper ... & 80 & $"$ & $12 \cdot 2$ & , & $11 \cdot 2$ & & $103 \cdot 4$ & , \\
\hline Tracing-cloth ..... & 35 & , & 150 & , & $54 \cdot 4$ & , & $104 \cdot 4$ & " \\
\hline Tracing-paper ...... & 22 & , & 70 & ” & $76 \cdot 0$ & , & 1050 & " \\
\hline
\end{tabular}

The numbers in the last column differ from the true value of 100 per cent. to a greater extent than can fairly be accounted for by the limits of experimental error. They are all over 100; and this was the case, not only for the tests here given, but also for every one of many seis of tests taken. The small discrepancy would be accounted for by assuming that the law of cosines is not exactly fulfilled. A very slight departure from this law would be amply suffleient to explain the results.

Suppose the candle-power of a unit aren of a diffusing surface in the direction of the normal is $\mathrm{B}$, and in any 
direction $\phi$ is

$$
\mathrm{B}(\cos \phi)^{1+\epsilon} \text {. }
$$

It is then easy to show that the total amount of light given out per unit area is equal to

$$
\pi \mathrm{B} \frac{1}{1+\frac{\epsilon}{2}}
$$

In all the above experiments the actual measurements have referred to the light receding from the diffusing substance at inclinations all practically normal to its surface. The quantity $B$ has been measured, the total light has been calculated as $\pi \mathrm{B}$, and has been overestimated in the ratio $1+\frac{\epsilon}{2}: 1$.

To account for an error of 5 per cent, the quantity $\epsilon$ need only be $0 \cdot 1$. The brightness of the surface (in the physiological sense) would, when viewed at an inclination $\dot{\phi}$, be proportional to

$$
\mathrm{B}(\cos \phi)^{1+\epsilon} / \cos \phi, \quad \text { or } \quad \mathrm{B}(\cos \phi)^{\epsilon} \text {. }
$$

This quantity is practically constant (if $\epsilon=0 \cdot 1$ ) until $\phi$ becomes very large. Its value is .994 for $\phi=20^{\circ}$ and $\cdot 974$ for $\phi=40^{\circ}$, and the change in the brightness of the surface would bardly be perceptible to the eye.

This correction applies to the coefficients $\eta_{2}$ and $\tau_{2}$; it does not affect the values of $\eta_{1}, \alpha$, or $\tau_{1}$. In some of the first tests of reflecting-power the inclination of the light-rays to the surface was considerably less than 90 degrees, and the values of $\eta$ obtained were less than those given above. These tests confirm the idea that the cosine law is not strictly fulfilled, but they were not accurate enough to be conclusive.

The above measurements were all made in the Optical Laboratory of the Central Institution, and the writer has had the benefit of the assistance of some of the students of that College in re-testing and confirming the results given in the foregoing tables.

XIII. Relation of Volta Electromotive Force to Pressure \&c. By Dr. G. Gone, F.R.S.*

TORTY-TWO years ago I made several experimental attempts to discover a difference of molecular state of the upper and lower ends of a vertical column of solution of cupric sulphate:-1st. By suddenly reversing the ends of a gutta-percha tube, about 6 feet high and 6 inches diameter, filled with the liquid, by swinging the tube in a vertical

* Oommunicated by the Author.

Note. Compare Wild's experiment (Wiedemann's Galvanismus, 1872, vol. i. p. 776; Pngg. Ann. 1835, vol. exxv. p. 119).

Plil. Mag. s. 5. Vol. 35. No. 213. Feb. 1893. 